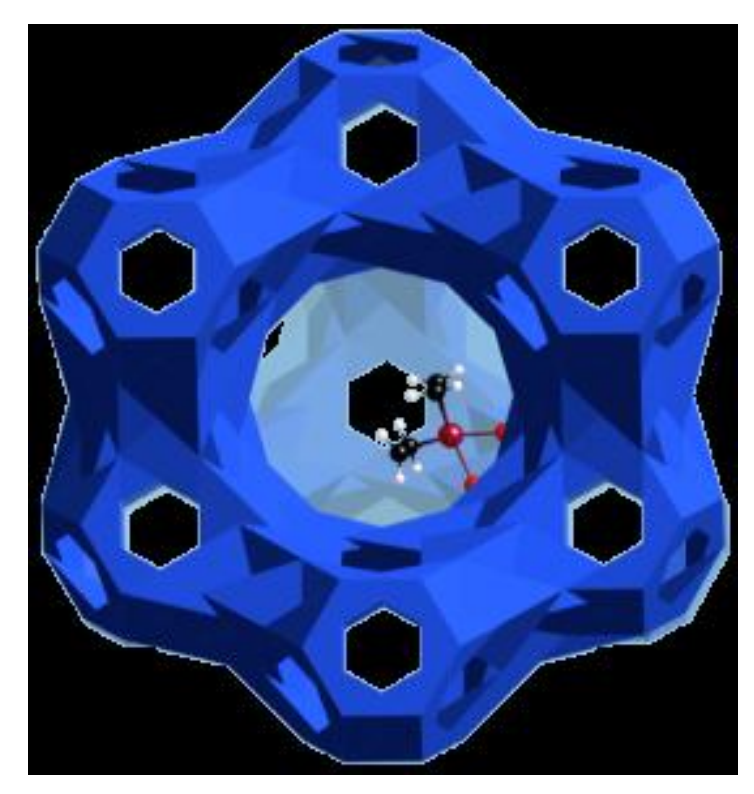

*Graphical Abstract
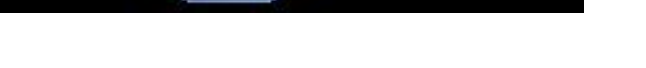


\title{
From Catalyst Preparation Toward Catalyst Synthesis
}

\author{
Bruce C. Gates ${ }^{a}$ \\ ${ }^{a}$ Department of Chemical Engineering and Materials Science, University of California, Davis, \\ California 95616, USA
}

KEY WORDS: catalyst synthesis, model catalyst, site-isolated catalyst, supported metal complex, supported molecular catalyst, tethered catalyst, tethered metal complex

\begin{abstract}
As catalysis research has evolved from resolution of functions such as metals and acids and experiments with model catalysts toward identification of catalytic sites, catalyst preparation has evolved toward catalyst synthesis. This argument is developed on the basis of examples of catalysts that are less complex structurally than typical industrial solid catalysts; the examples include metal complexes bonded to supports, through tethers or metal-oxygen bonds, and crystalline porous materials such as zeolites. With such materials, especially molecular species bonded to crystalline supports, catalyst synthesis is a reality and the notion of catalyst design is becoming realistic.
\end{abstract}

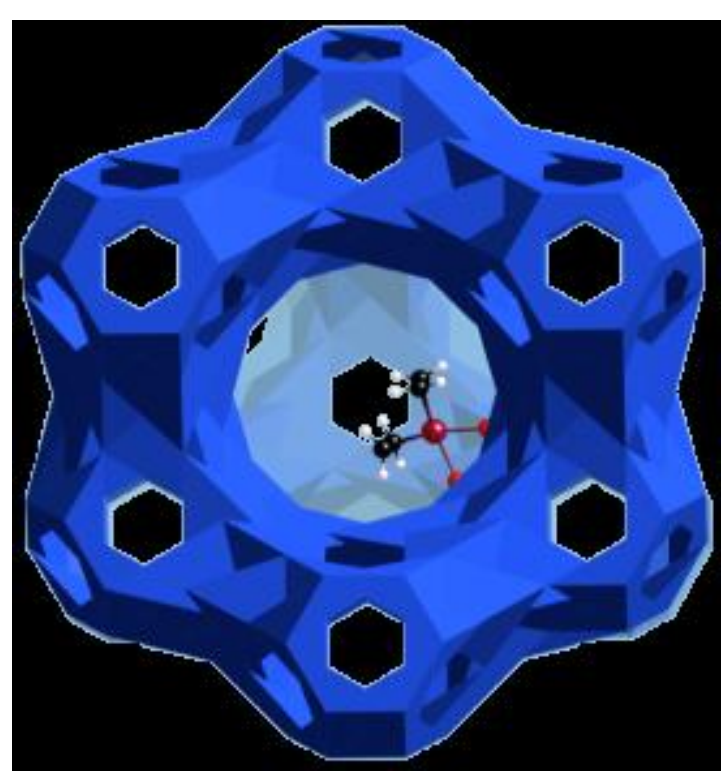


Unless technological catalysts are economical, robust, and reliable, their activities and selectivities don't matter. Scale of manufacture and economy dictate that most catalysts are highly nonuniform materials, typically incorporating multiple phases with various compositions, degrees of crystallinity, and surface structures that vary on length scales from Ångstroms to centimeters. Promoters and binders add to the complexity, which increases during use with accumulating deposits and changing structures and compositions.

To a technologist, this complexity spells opportunity for competitive advantage. To a scientist, it is a barrier to fundamental understanding.

A route to better catalysts, beyond rote testing, is through identification of catalytic functions. Improvements result when the functions are resolved and then combined optimally. The functions may be associated with components such as a metal, support, or promoter. Haensel's early work [1] on petroleum naphtha reforming illustrates the approach that led to $\mathrm{Pt} / \mathrm{Al}_{2} \mathrm{O}_{3}$, the prototype bifunctional catalyst. Platinum catalyzes hydrogenation and dehydrogenation reactions (with dehydrocyclization, etc.), and the acidic (chlorided) alumina (a) forms carbocationic intermediates from olefins that are products of metal-catalyzed paraffin dehydrogenation and (b) catalyzes olefin isomerization. Weisz and Swegler [2] did experiments with particles of $\mathrm{Pt} / \mathrm{SiO}_{2}$ mixed with particles of acidic silica-alumina to demonstrate (a) the importance of the transport of intermediate olefins between the separate metal and acid functions and (b) the benefit of juxtaposing these functions. Understanding of these bifunctional catalysts was essential to improvements in naphtha reforming technology, and it paved the way to industrial catalysts for hydrocracking [3] and hydroisomerization [4] of paraffins.

Beyond understanding of catalyst functions, researchers strive to understand catalytic sites. Years of fundamental work by the Haldor Topsøe organization and their collaborators on hydrodesulfurization (HDS) catalysts led to such understanding [5]. Investigations of the surface chemistry of alumina supports and their acidic sites [6] and of catalysts in the pre-sulfided state [5] were complemented with extensive fundamental work on $\mathrm{MoS}_{2}$, which provides the principal functions catalyzing HDS and hydrogenation reactions. Scanning tunneling microscopy (STM) images characterizing promoted and unpromoted $\mathrm{MoS}_{2}$ nanoclusters mounted on unreactive single-crystal $\mathrm{Au}(111)$ supports identified the catalytic sites as electron-rich, metallike sulfur atoms at the $\mathrm{MoS}_{2}$ layer edges [7]. Promoter cobalt atoms located near those sites change the nanocluster morphology and the electronic structure of the sulfur edges. Images, spectra, and calculations based on theory determined how thiophene bonds and reacts with hydrogen at the catalytic sites. Transmission electron microscopy images of complex HDS catalysts show $\mathrm{MoS}_{2}$ in sheets that are only several atomic layers thick [8]. All these results, combined with efficient catalyst screening, presumably helped guide catalyst manufacturers to 
make supported catalysts with small, stable $\mathrm{MoS}_{2}$ nanoclusters with optimal access to the layer edges and placement of the promoters.

The Haldor Topsøe organization is well known for building technology on the foundation of fundamental understanding meshed with efficient catalyst testing - not only in HDS, but in ammonia synthesis, steam reforming of hydrocarbons, and others. Details are presented elsewhere in this volume, and the goal of this essay is not to elaborate on these examples but rather to defend the thesis that research strategies have gone well beyond resolving catalyst functions and elucidating catalytic sites by investigating simplified (model) catalysts: now catalyst preparation is morphing into catalyst synthesis, and flirtations with the notion of catalyst design are becoming serious.

Synthesis has become a realistic term for several classes of catalysts:

- supported metal complexes, including those

O tethered to support surfaces or

o bonded directly to support surfaces, and

- Crystalline porous materials (molecular sieves).

Such catalysts are used extensively in technology: for example, supported complexes of chromium and other metals are used for olefin polymerization, and acidic molecular sieves are used for petroleum and petrochemical conversions.

If the structures of the most selective and active catalytic sites were known, the design goal would be to synthesize them (alone) and stabilize them on supports. Foundations for anticipating good catalytic sites include extrapolations from understanding of known catalysts-not just those that work on surfaces-and theory. The examples that follow illustrate how this approach is taking hold with catalysts that are relatively simple in structure.

Because they are similar to molecular catalysts in solution, catalytic species tethered to supports are a good starting point. Examples are sulfonic acid groups bonded to organic polymers through $\mathrm{C}-\mathrm{S}$ bonds and metal complexes bonded to $\mathrm{SiO}_{2}$ through $\mathrm{O}-\mathrm{Si}-\mathrm{C}$ links that may incorporate tethers with hydrocarbon chains [9]. Work on tethered catalysts gained traction several decades ago as researchers saw how to synthesize supported complexes of metals used in large-scale homogeneous catalytic processes, such as olefin hydrogenation, olefin hydroformylation, methanol carbonylation, and Heck and Suzuki coupling. The metal complexes were often bonded to tethered ligands such as phosphines that were known from homogeneous catalysis to provide good electron-donor properties. When the tether chains are 
long enough, when solvent is present, and when the support is inert, the catalytic groups act essentially as they do in solution, with a negligible support influence. Synthesis of such catalysts is often straightforward.

Research on these catalysts continues to be vigorous, but it went into a decline when it became evident that the metals often leak from the supports. Key results emerged from flowreactor experiments [10] demonstrating that polymer-supported phosphine- or aminecomplexed rhodium was slowly unlinked from the support and migrated downstream in the packed-bed reactor during operation with liquid-phase reactants. We now realize that catalyst stability requires that the metal be bonded strongly to a firmly anchored tether at every step of the catalytic cycle (but elucidation of a full catalytic cycle is often a daunting task). Determination of the true nature of the catalytic species is challenging because traces of leaked species in solution may do the catalysis, or reduced metal in the form of clusters or particles may be responsible $[11,12]$.

A simple form of supported metal complex catalyst has found large-scale application. The reaction is methanol carbonylation to give acetic acid, and the catalyst is rhodium carbonyl complexes supported on an anion-exchange resin $[13,14]$. A catalytic cycle postulated for the reaction in solution shows that each rhodium complex in the cycle is anionic $\left(\left[\mathrm{Rh}(\mathrm{CO})_{2} \mathrm{I}_{2}\right]^{-}\right.$and species formed from it)-and therefore stably ion-paired to the pyridinium groups of the resin. Thus, the supported catalyst acts like the soluble analogue and evidently resists leakage.

The catalyst synthesis can be described as precise. The same could be said about acidform ion-exchange resins synthesized, for example, by sulfonation of crosslinked polystyrene. When sulfonic acid resins are used in excess liquid water, the catalytic species are dissociated, hydrated protons, and the support doesn't matter much. But when liquid water is not present, then the catalytic sites are $-\mathrm{SO}_{3} \mathrm{H}$ groups, but these usually do not act alone, instead interacting with each other via hydrogen bonding and working in concert in ways that depend on the properties of the support and the nature of the groups bonded to them [15].

Translation of molecular catalysis form solutions to supports is less straightforward when the metals are anchored directly to the supports by bonding to oxygen atoms. Examples are the silica-supported chromium complexes used on a massive scale for ethylene polymerization, the subject of an exhaustive review by McDaniel [16], whose assessment indicates a daunting complexity of these catalysts, which do not incorporate uniform surface species. Questions remain about the ligands bonded to the chromium, the oxidation states of the chromium, the number of chromium atoms in the catalytic species, and the fraction of the chromium sites that are active. These catalysts can be made from various precursors, including organometallics, and some syntheses can be described as precise [17], but this topic continues 
to challenge and vex researchers, although details of the catalysts and their performance are gradually emerging $[17,18]$.

One of the motivations for using supported metal complex catalysts is to dial in selectivity, based on the realization that the metal complexes used in industrial homogeneous catalytic processes are highly selective-the selectivity is associated with the unique (molecular) catalyst structures. Countless supported metal complexes (e.g., of rhodium and iridium) have been found to catalyze olefin hydrogenation, more or less as in solution. These examples provided a starting point in the search for a supported metal complex catalyst for the selective hydrogenation of 1,3-butadiene to butenes [19]. At some level, the catalyst was designed; the "design variables" are the metal, the ligands bonded to it (which include the support), and the number of metal atoms constituting a catalytic site [20]. The ligands on the metal in the catalytic cycle usually include those derived from the reactants (e.g., hydride from $\mathrm{H}_{2}$ and alkyl from olefins), among others, even those that may decrease the catalytic activity, such as $\mathrm{CO}$, a well-known catalyst poison.

A highly selective catalyst for the diene hydrogenation emerged from experiments with samples synthesized in reactions of $\mathrm{Rh}\left(\mathrm{C}_{2} \mathrm{H}_{4}\right)_{2}$ (acac) (acac is acetylacetonate) with supports to form Rh-O bonds; manipulation of the surface organometallic species was guided by the "design variables" listed above [19]. The strategy was to tune the reactivities of the ligands on rhodium formed from the reactants; to select the number of Rh atoms in the catalytic sites to test for a benefit of adjacent rhodium centers for bonding of the various ligands (including the bifunctional olefin); and to find a combination of ligands to limit the hydrogenation to one of the diene double bonds. Experiments showed that when the good electron donor MgO was the support for dimeric species initially present as $\mathrm{Rh}_{2}(\mathrm{CO})_{6}$, both $\mathrm{H}_{2}$ and 1,3-butadiene reacted with the rhodium centers, and high catalytic selectivities to $n$-butenes were achieved (>99\%) at conversions as high as $97 \%$ [20]. The CO ligands on the rhodium are selective poisons, hindering hydrogenation, especially of the product butenes. The catalyst lost selectivity (a) when the CO was removed and (b) when the diene conversions were high (>97\%), because then the excess of butenes over diene in contact with the catalyst allowed the butenes to bond to rhodium sufficiently in competition with the otherwise preferentially bonded diene to be hydrogenated. The supported rhodium dimer catalyst is not used in industry, but it is appealing because of its high activity and selectivity and the strong incentive to remove diene impurities from butene feeds to polymerization reactors, because co-polymerized diene diminishes the polymer quality.

This supported rhodium dimer catalyst, like the supported chromium complexes, is regarded as site-isolated and essentially molecular in character. Work on this broad class of catalyst is proceeding rapidly today, as researchers have learned how to make atomically 
dispersed noble metals bonded to a numerous metal oxides and zeolites. Surprising to many, a number of these catalysts are rather stable [21]. The metals are present as cations bonded to oxygen atoms of the supports, but the other ligands on the metals are often not known. Examples include atomically dispersed gold, iridium, osmium, and platinum on supports such as $\mathrm{Y}-\mathrm{Al}_{2} \mathrm{O}_{3}, \mathrm{MgO}$, iron oxides, and zeolites $[21,22]$. Such catalysts are active for reactions such as $\mathrm{CO}$ oxidation and the water gas shift. Lots of opportunity remains to elucidate how the supports as ligands affect the catalytic properties. Part of the attraction of these catalysts is the high dispersion of the metals and therefore their efficient use as catalysts. As the science progresses, the preparations of these catalysts will take on more of the character of precise syntheses.

The term synthesis is also widely applied to one of the most important classes of catalytic materials, molecular sieves, including zeolites. The usage is a bit liberal, as essentially all new zeolite catalysts are found by trial-and-error experimentation, albeit guided by the selection of solvents and templates to help produce desired pore structures. Modifications of zeolites are carried out with some precision as well, illustrated by delamination [23, 24] and other methods [25] to create pores between crystalline regions to increase accessibility to the pore openings.

Molecular sieves have high degrees of uniformity by comparison with typical industrial catalysts, but they nonetheless incorporate gradients in composition and are not always pure phases. It seems fair to state that preparation of large-scale catalytic materials comes closest to synthesis when the materials are molecular sieves. It is also true that molecular sieves are among the most nearly uniform of catalyst supports, and they incorporate sites such as acidic $\mathrm{OH}$ groups located at $\mathrm{Al}$ sites in aluminosilicates, and these are rather well-defined although not all equivalent. Thus, these crystalline materials are in a sense close to ideal in structure and therefore offer some the best opportunities for precise synthesis of supported catalysts.

For example, $\mathrm{Au}\left(\mathrm{CH}_{3}\right)_{2}$ (acac) reacts with sites on zeolite $\mathrm{NaY}$ to give site-isolated gold cations, which catalyze CO oxidation [26]. The heavy Au atoms can be imaged with scanning transmission electron microscopy, which determines their locations-in only two kinds of sites within the crystalline zeolite. Platinum ions introduced as salts into a zeolite and treated to remove the amine ligands also remain site isolated and catalyze CO oxidation, and, again, imaging determined the locations of the Pt atoms [27]. Thus, as syntheses of supported metals with nearly molecular structures are carried out on nearly uniform molecular sieve supports, the goal of precise catalyst synthesis is being more and more closely approached.

Such materials offer prospects as nearly uniform, understandable, and potentially selective catalysts, and these prospects account for the growing attention paid them by researchers. It is possible in prospect to determine almost unequivocally when some metal 
complexes on zeolite supports are the catalytic sites (although the ligands may remain unknown). Such determinations require syntheses that lead to uniform supported species and thorough evidence of the stable bonding of the metal to the support, the retention of siteisolation as checked by microcopy and spectroscopy, the uniformity of the supported catalytic species as demonstrated in catalyst poisoning experiments, and the retention of catalytic activity in repeat experiments. Finke's group provided an example of such a thorough characterization with a zeolite-supported iridium complex catalyst used for cyclohexene hydrogenation [28]. Because of their relative simplicity, catalysts such as this are not representative of solid catalysts generally, but they are a wedge toward progress in the direction of catalyst synthesis and design.

\section{Acknowledgment}

Thanks to DOE, Office of Science, Basic Energy Sciences, for support via grant DEFG0204ER15513.

\section{References}

[1] M. J. Sterba and V. Haensel, Ind. Eng. Chem. Prod. Res. Dev. 15 (1976) 2.

[2] P. B. Weisz, E. W. Swegler, Science 126 (1957) 31.

[3] J. Weitkamp, ChemCatChem 4 (2012) 292.

[4] C. Perego, V. Calemma, P. Pollosel, in Zeolites and Catalysis Synthesis, Reactions, and Applications, (Ed.: J. Cejka, A. Corma, S. Zones), Wiley-VCH, Weinheim, 2012, p. 585.

[5] H. Topsøe, B. S. Clausen, F. E. Massoth, Hydrotreating Catalysts, Springer, Berlin, 1996.

[6] N. Y. Topsøe, H. Topsøe, F. E. Massoth, J. Catal. 119 (1989) 252.

[7] J. V. Lauritsen, F. Besenbacher, Adv. Catal. 50 (2006) 97.

[8] F. Delanny, Appl. Catal. 16 (1985) 135.

[9] C. Baleizao, B. Gigante, H. Garcia, A. Corma, J. Catal. 215 (2003) 199.

[10] W. H. Lang, A. T. Jurewicz, W. O. Haag, D. D. Whitehurst, L. D. Rollmann, J. Organomet. Chem. 134 (1077) 85.

[11] N. T. S. Phan, M. Van Der Sluys, C. W. Jones, Adv. Synth. Catal. 348 (2006) 609.

[12] J. E. Mondloch, E. Bayram, R. G. Finke, J. Mol. Catal. A: Chem. 355 (2012) 1. 
[13] N. Yoneda, S. Kusano, M. Yasui, P. Pujado, S. Wilcher, Appl. Catal. A: Gen. 221 (2001) 253.

[14] T. Minami, K. Shimokawa, K. Hamato, Y. Shiroto, N. Yoneda, US Patent 5364963, 1994.

[15] B. C. Gates, Handbook of Heterogeneous Catalysis, $2^{\text {nd }}$ Edition, Eds. G. Ertl, H. Knözinger, F. Schüth, J. Weitkamp, Verlag Chemie, Weinheim, Vol. 1, p. 278, 2008.

[16] M. P. McDaniel, Adv. Catal. 53 (2010) 123.

[17] Z. Liu, X. He, R. Cheng, M. S. Eisen, M. Terano, S. L. Scott, B. Liu, Adv. Chem. Eng. 44 (2014) 127.

[18] M. F. Delley, F. Nunez-Zarur, M. P. Conley, A Comas-Vives, G. Siddiqi, S. Norsic, V. Monteil, O. V. Safonova, C. Coperet, Proc. Nat. Acad. Sci. US 111 (2014) 11624.

[19] D. Yardimci, P. Serna, B. C. Gates, ACS Catal 2 (2012) 2100.

[20] P. Serna, B. C. Gates, Acct. Chem. Res., in press, 2014.

[21] M. Flytzani-Stephanopoulos, Acct. Chem. Res. 47 (2014) 783.

[22] M. Flytzani-Stephanopoulos, B. C. Gates, Ann. Rev. Chem. Biomol. Eng. 3 (2012) 545.

[23] U. Diaz, A. Corma, Dalton Trans. 43 (2014) 10292.

[24] A. Corma, V. Fornes, J. Martinez-Triguero, S. B. Pergher, J. Catal. 186 (1999) 57.

[25] I. Ogino, M. M. Nigra, S. J. Hwang, J. M. Ha, T. Rea, S. I. Zones, A. Katz, J. Am. Chem. Soc. 133 (2013) 3288.

[26] J. Lu, C. Aydin, N. D. Browning, B. C. Gates, Angew. Chem. Int. Ed. 51 (2012) 5842.

[27] J. D. Kistler, N. Chotigkrai, P. Xu, B. Enderle, P. Praserthdam, C. Y. Chen, N. D. Browning, B. C. Gates, Angew. Chem. Int. Ed. 53 (2014) 8904.

[28] E. Bayram, J. Lu, C. Aydin, A. Uzun, N. D. Browning, B. C. Gates, R. G. Finke, ACS Catal. 2 (2012) 1947. 